\title{
Separating Myth from Reality in Education: Introduction to the Special Issue
}

\author{
Andrew C. Butler ${ }^{1} \cdot$ Shana K. Carpenter ${ }^{2}$
}

Published online: 31 October 2015

(C) Springer Science+Business Media New York 2015

The field of education contains a diversity of practices that are intended to facilitate learning (e.g., learning activities and pedagogical methods). Practitioners, administrators, and students also hold many beliefs about learning that guide their approach to education. Although some of these practices and beliefs are supported by empirical findings from rigorous scientific research, many others have little or no evidence to support them. In order to improve education, it is critical to identify effective practices and accurate beliefs. Correspondingly, it is also critical to correct misconceptions about ineffective practices and inaccurate beliefs. In this special issue, Educational Psychology Review examines some common practices and beliefs in education with the goal of contributing to the ongoing effort to separate myth from reality.

Each article in this special issue evaluates the evidence that supports a common educational practice or belief. In addition to providing valuable information about the evidence to support specific practices or beliefs, all of the articles model an evaluation process that could be applied to other practices and beliefs. The authors begin by defining and documenting the existence of the practice or belief. Next, they delineate criteria for evaluating the efficacy of the practice or the accuracy of the belief (i.e., How can this practice or belief be evaluated experimentally? What would constitute good evidence? What evidence should be disqualified and why?). After setting up objective criteria, they describe and evaluate the evidence for and against the practice or belief. Finally, they draw conclusions based on the strength and credibility of the evidence, discuss the implications for education, and provide recommendations for future research.

Using this framework, each article in the special issue addresses a unique topic relevant to current beliefs and practices about learning. Some of the articles evaluate widely held intuitive beliefs about learning that turn out to be unsupported by empirical evidence. Finn and Tauber (2015) review the literature on the pervasive and misleading effect of the fluency of cognitive processing on students' perceptions of learning. Situations that increase the fluency or ease of processing are widely believed by students to be efficacious for learning. However, the

Andrew C. Butler

andrewbutler@austin.utexas.edu

1 University of Texas at Austin, Austin, TX, USA

2 Iowa State University, Ames, IA, USA 
opposite is often true-strategies and techniques that increase the perceived difficulty of learning and decrease the sense of fluency (e.g., self-testing and spaced practice) often lead to superior long-term learning. Finn and Tauber discuss the origins of these highly intuitive yet erroneous beliefs and offer several suggestions for overcoming the deleterious effects of overreliance on fluency as a heuristic for making judgments about learning.

The article by Rittle-Johnson et al. (2015) also evaluates an intuitive belief: the belief that in mathematics learning the development of conceptual knowledge (i.e., the understanding of general mathematics principles) precedes that of procedural knowledge (i.e., how to carry out a series of steps to solve a problem). Based on this belief, many people advocate that instruction should take place in a conceptual-to-procedural order. To the contrary, the authors' review of the evidence finds that the development of both types of knowledge is a "two-way" street, that is, the evidence supports the idea that advances in procedural knowledge can improve conceptual knowledge and vice versa. They conclude that there may be more than one way to arrange the order of instruction to enhance mathematics achievement.

Silvia (2015) addresses yet another intuitive belief: the long-standing assumption that intelligence and creativity are distinct and unrelated abilities. Based on recent advances in assessment techniques, statistical analyses, and theoretical development, Silva evaluates this belief and concludes that intelligence and creativity actually have much more in common than previously thought. He further argues that recognizing the connections between the two abilities enriches our understanding of each ability and provides new approaches for assessing them.

Other articles in the special issue address the effectiveness of interventions that are currently popular in education. Stieff and Uttal (2015) evaluate whether interventions that are designed to improve spatial ability increase STEM achievement. Drawing from decades of research demonstrating a positive relationship between spatial ability and STEM achievement, researchers and educators have developed interventions to train spatial ability with the expectation that it will produce better STEM achievement. Although a handful of studies to date suggest some promising effects of spatial training on STEM achievement, the authors conclude that further research is needed to evaluate this claim, calling for the use of rigorous methodology that can determine the degree to which spatial training directly improves achievement, retention, and degree attainment among STEM students.

Redick et al. (2015) evaluate another popular intervention: working memory training programs. They review the evidence to-date on the efficacy of working memory training on children's academic and intellectual achievement. They conclude that these programs appear to produce some short-term gains on tasks that are similar to the training activities, but they find no compelling evidence of consistent long-term gains on academic achievement in reading, mathematics, and spelling. The practical implications of the articles by Stieff and Uttal (2015) and Redick et al. (2015) are that caution should be exercised in deciding whether or not to implement these two educational interventions.

The final two articles in the special issue discuss the ways in which well-known and seemingly simple instructional techniques may affect learning in complex and sometimes unexpected ways. Rohrer (2015) evaluates the widely endorsed principle that distributing practice over longer periods of time produces better learning than massing practice within a short period of time. He finds that the overwhelming majority of studies in both the laboratory and the classroom support the idea that long-term learning is maximized when instruction is distributed rather than massed. However, Rohrer also reviews a small number of studies on foreign language learning, which present a possible exception to this principle; these studies appear to demonstrate that shorter, condensed courses appear to benefit learning more than 
longer, non-condensed courses. He notes that methodological issues preclude firm conclusions, and thus, more research is needed to untangle this complex principle.

Nokes-Malach et al. (2015) assess the effectiveness of another popular instructional technique: collaborative learning. They describe the popular appeal of students working together to solve problems and acquire new knowledge. However, their review of the evidence suggests that collaborative learning can be both beneficial and detrimental depending on the circumstances. The authors identify several individual and situational factors (e.g., student characteristics and the type of activities students are engaged in) that can influence whether students learn more effectively by working individually or in groups. Based on the literature to date, they offer insights to educators about the factors that should be considered when incorporating collaborative activities into educational practice.

In summary, the findings reported in this special issue represent valuable and timely information for researchers, educators, administrators, and policy-makers. The evaluative process used by the authors of these articles provides a roadmap for evaluating other practices and beliefs in education as well as other fields. One particular element that is critical to the evaluation process is the delineation of objective criteria for judging the efficacy of practices or accuracy of beliefs. Many of the disagreements about practices and beliefs stem from a lack of common understanding about criteria for evaluating claims. Without a common understanding and agreement about what constitutes good evidence, it is incredibly difficult to reach consensus about the efficacy of a practice or the accuracy of a belief. Much progress has been made in the movement to increase evidence-based practices in education; however, as this special issue illustrates, there is still a lot of work to be done in separating myth from reality in education.

\section{References}

Finn, B., \& Tauber S. K. (2015). When confidence is not a signal of knowing: how students' experiences and beliefs about processing fluency can lead to miscalibrated confidence. Educational Psychology Review. doi: 10.1007/s10648-015-9313-7.

Nokes-Malach, T. J., Richey, J. E., \& Gadgil, S. (2015). When is it better to learn together? Insights from research on collaborative learning. Educational Psychology Review. doi:10.1007/s10648-015-9312-8.

Redick, T. S., Shipstead, Z., Wiemers, E. A., Melby-Lervåg, M., \& Hulme, C. (2015). What's working in working memory training? An educational perspective. Educational Psychology Review. doi:10.1007/ s10648-015-9314-6.

Rittle-Johnson, B., Schneider, M., \& Star, J. R. (2015). Not a one-way street: bidirectional relations between procedural and conceptual knowledge of mathematics. Educational Psychology Review. doi:10.1007/ s10648-015-9302-x.

Rohrer, D. (2015). Student instruction should be distributed over long time periods. Educational Psychology Review. doi:10.1007/s10648-015-9332-4.

Silvia, P. J. (2015). Intelligence and creativity are pretty similar after all. Educational Psychology Review. doi:10. 1007/s10648-015-9299-1.

Stieff, M., \& Uttal, D. (2015). How much can spatial training improve STEM achievement? Educational Psychology Review. doi:10.1007/s10648-015-9304-8. 